\title{
Fermentative Production of Value-Added Products from Lignocellulosic Biomass
}

\author{
Silvio S. da Silva, ${ }^{1}$ Anuj K. Chandel, ${ }^{1}$ S. Ranil Wickramasinghe, ${ }^{2}$ and José M. G. Domínguez ${ }^{3}$ \\ ${ }^{1}$ Department of Biotechnology, Engineering School of Lorena, University of São Paulo, Estrada Municipal do Campinho, \\ Caixa Postal 116, 12602-810 Lorena, SP, Brazil \\ ${ }^{2}$ Ralph E. Martin Department of Chemical Engineering, University of Arkansas, Fayetteville, \\ AR 72701, USA \\ ${ }^{3}$ Chemical Engineering Department, University of Vigo, Campus Ourense, As Lagoas s/n, 32004 Ourense, Spain
}

Correspondence should be addressed to Silvio S. da Silva, silvio@debiq.eel.usp.br

Received 22 November 2012; Accepted 22 November 2012

Copyright (c) 2012 Silvio S. da Silva et al. This is an open access article distributed under the Creative Commons Attribution License, which permits unrestricted use, distribution, and reproduction in any medium, provided the original work is properly cited.

Bioconversion of lignocellulosic biomass (agro residues, grasses, wood, weed, dedicated energy crops and others) into biofuels and other value-added products offers numerous geopolitical, environmental, and strategic benefits. Lignocellulosic biomass (LB) is the most abundant renewable organic resources ( 200 billion tons annually) on earth that are readily available for conversion to biofuels and other value-added products (industrial enzymes, organic acids, pharmaceuticals, commodity chemicals, and food/feed). However, they have not yet been tapped for the commercial production of these products.

The last three decades witnessed the success made in research and development for the conversion of LB into biofuels and other commercially viable products. Despite the success achieved in the laboratory, there are several challenges for the successful bioconversion of lignocellulosic substrates into value-added products at commercial scale. The future of lignocellulosics conversion is expected to lie in improvement in pretreatment technologies, cellulolytic enzymes producing microorganisms, fullest exploitation of biomass components, and process integration. Further, advancement in system-biology-based "OMICS" approaches may provide new breakthroughs for the development of biocatalysts/enzyme titers for the cost effective production of commodity chemicals and fuels from biomass.

This special issue presents a diverse range of experimental advancements on biomass pretreatment, enzymatic saccharification, production of cellulosic biofuels, polyhydroxyalkanoates (PHA), polyhydroxybutyrate (PHB), and lovastatin and blends of polyacrylonitrile (PAN) and lignin. Authors here report on process variables including feedstock types (grasses and sugarcane-based agro residues), bioprocess engineering simulations, multivisual structural analysis of lignocellulosics after pretreatment, improvements in cellulase-mediated hydrolysis, and modification in fermentation strategies for the production of a range of valueadded products.

Selection of suitable lignocellulosic substrates plays a key role for the economic cellulosic ethanol production. Factors such as availability of feedstock and presence of high amount of carbohydrates and lignin amounts are critical for biofuels production at large scale under the biorefinery concept. Of particular interest in this regard is the use of sugarcane residues, corn stover, and grasses as a second-generation feedstock. L. Canilha et al. comprehensively reviewed the technologies (pretreatment methods, detoxification, hydrolysis, fermentation, and end-product distillation) for secondgeneration $(2 \mathrm{G})$ ethanol production from sugarcane residues (sugarcane bagasse and straw). Grasses are another excellent feedstock for $2 \mathrm{G}$ ethanol production in countries like Thailand. J. Wongwatanapaiboon et al. collected data on composition of cellulose, hemicellulose, and lignin in 18 types of grasses followed by the alkaline peroxide mediated pretreatment. The pretreated materials were evaluated for ethanol production under simultaneous saccharification and fermentation approach employing yeasts cocultures. $\mathrm{J}$. Lu et al. explored the Reed as a primary source for $2 \mathrm{G}$ ethanol production. They presented the data on sugar 
recovery after liquid hot water pretreatment followed by enzymatic hydrolysis and conversion of sugars into ethanol under separate hydrolysis and fermentation. J. E. Jessen and J. Orlygsson examined the $2 \mathrm{G}$ ethanol production from various feedstocks (hemp stem, grass, wheat straw, newspaper, and cellulose) employing a new thermophilic isolate, Thermoanaerobacter $\mathrm{J} 1$, from a hot spring in Iceland in addition to the exploration of a mechanism of electronscavenging systems on end-product formation. For the economization of biofuel or any value-added product formation from lignocellulosic materials, the efficient bioconversion of cellulose and hemicellulose into monomeric sugars is inevitable. In this line, A. D. Eckard et al. demonstrated the mechanism of casein (skimmed milk protein) action to improve the enzymatic saccharification of corn stover.

Pretreatment is the key technology for the direct methanation of agroresidues. Y. Feng et al. investigated the changes in the maize straw characteristics during the methanation process. M. A. K. M. Zahari et al. optimized major influential parameters for poly(3-hydroxybutyrate) production from oil palm frond (OPF) juice by Cupriavidus necator CCUG52238T and concluded that OPF juice could be a competitive carbon source for the economic production of PHB. P. Chakraborty et al. presented the data on modified feeding strategies using a mixture of volatile fatty acids and artificial rumen fluid to maximize the PHA production by Ralstonia eutropha. Towards the pharmaceuticals intermediate production, M. F. Jahromi et al. investigated the lovastatin production by Aspergillus terreus under solidstate fermentation using rice straw and oil palm frond. M. Ö. Seydibeyoğlu examined the properties of blends of polyacrylonitrile (PAN) and lignin followed by the structural analysis employing modern structural tools.

We sincerely hope readers will find these papers helpful to their research pursuits. It has been our pleasure to put together this special issue in Journal of Biomedicine and Biotechnology.

\section{Acknowledgments}

We thank all of the contributing authors for sharing their quality research through this special issue. Editors would like to thank the reviewers for their critical comments and suggestions which helped to improve the quality of the papers.

Silvio S. da Silva

Anuj K. Chandel

S. Ranil Wickramasinghe

José M. G. Dominguez 

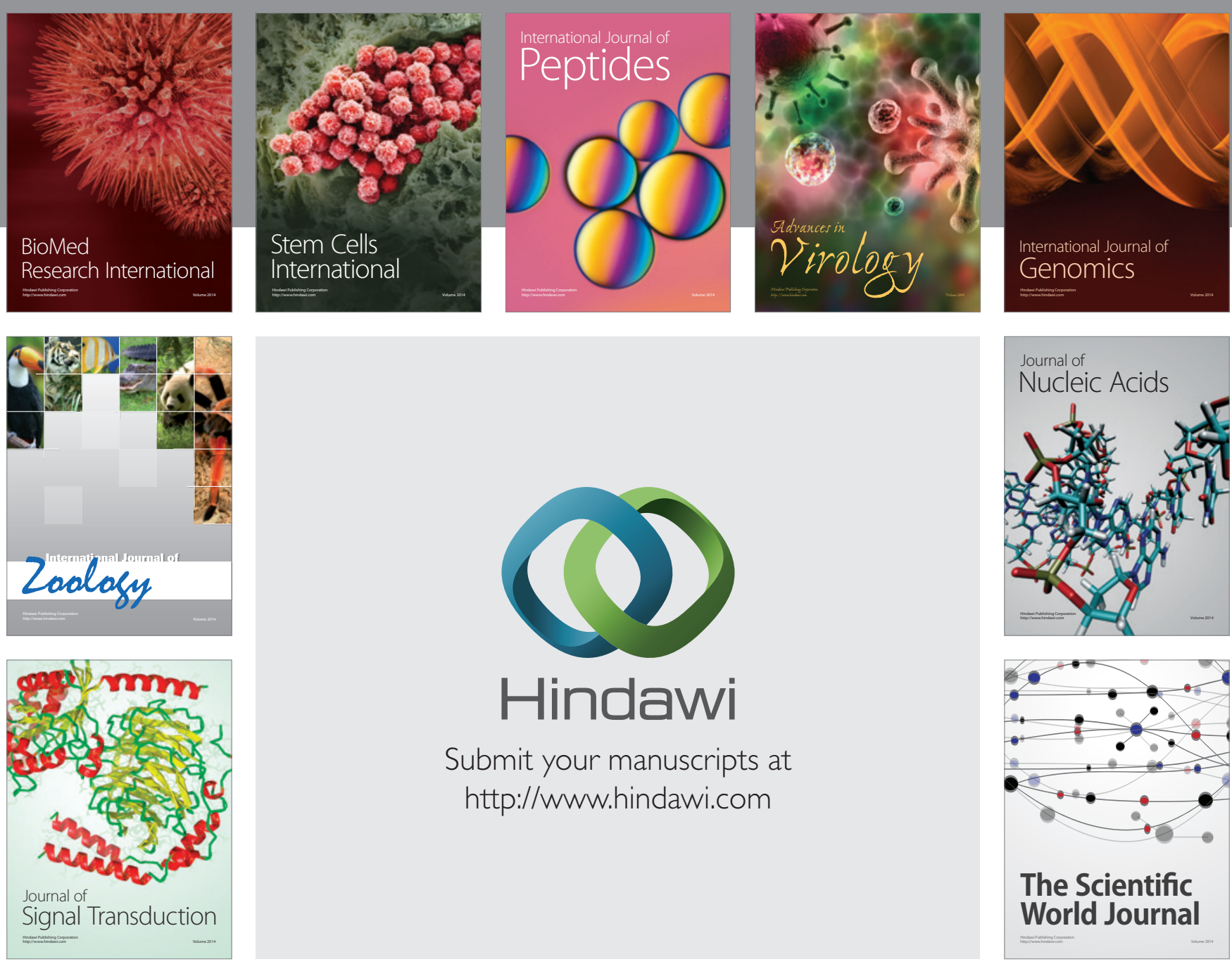

Submit your manuscripts at

http://www.hindawi.com
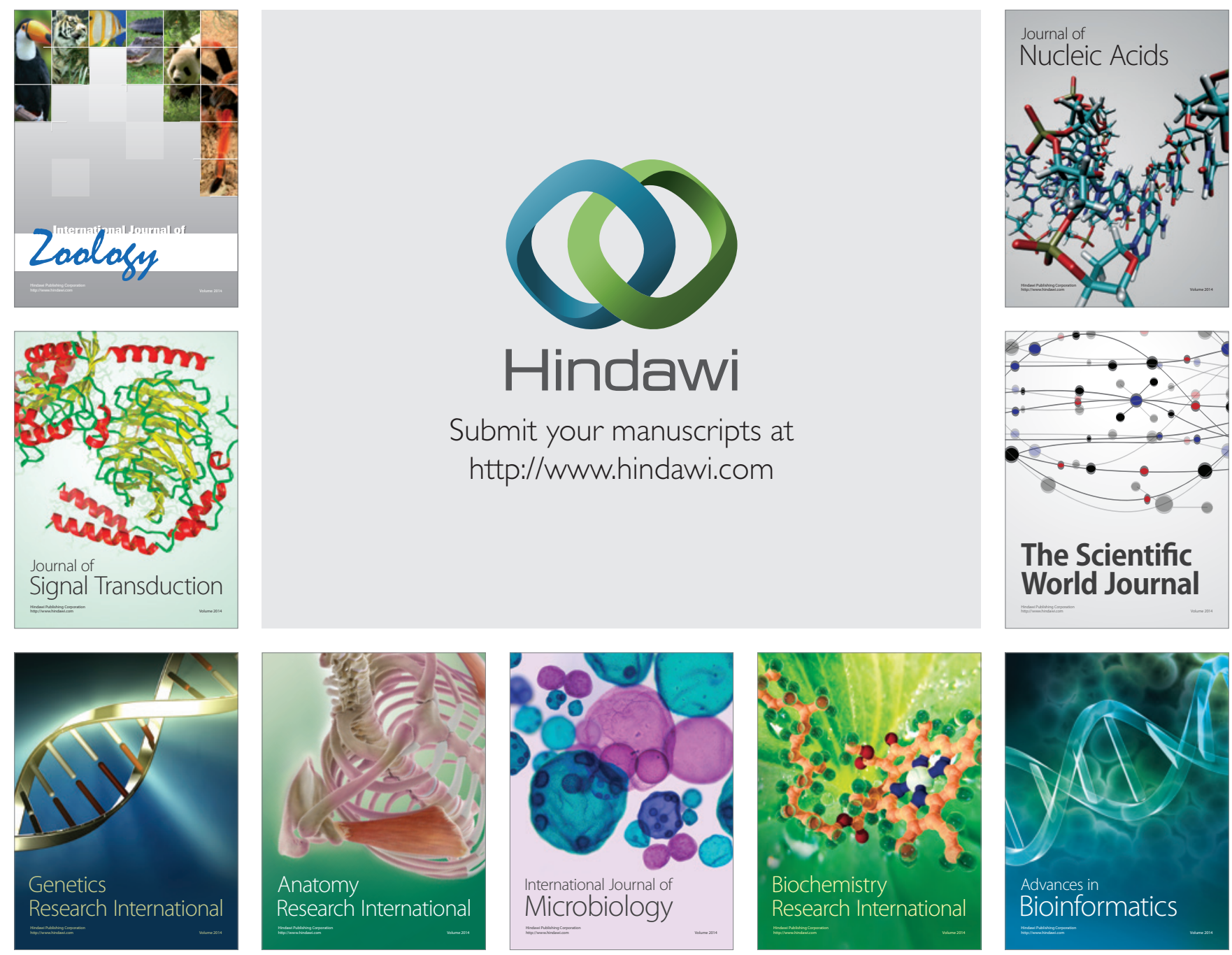

The Scientific World Journal
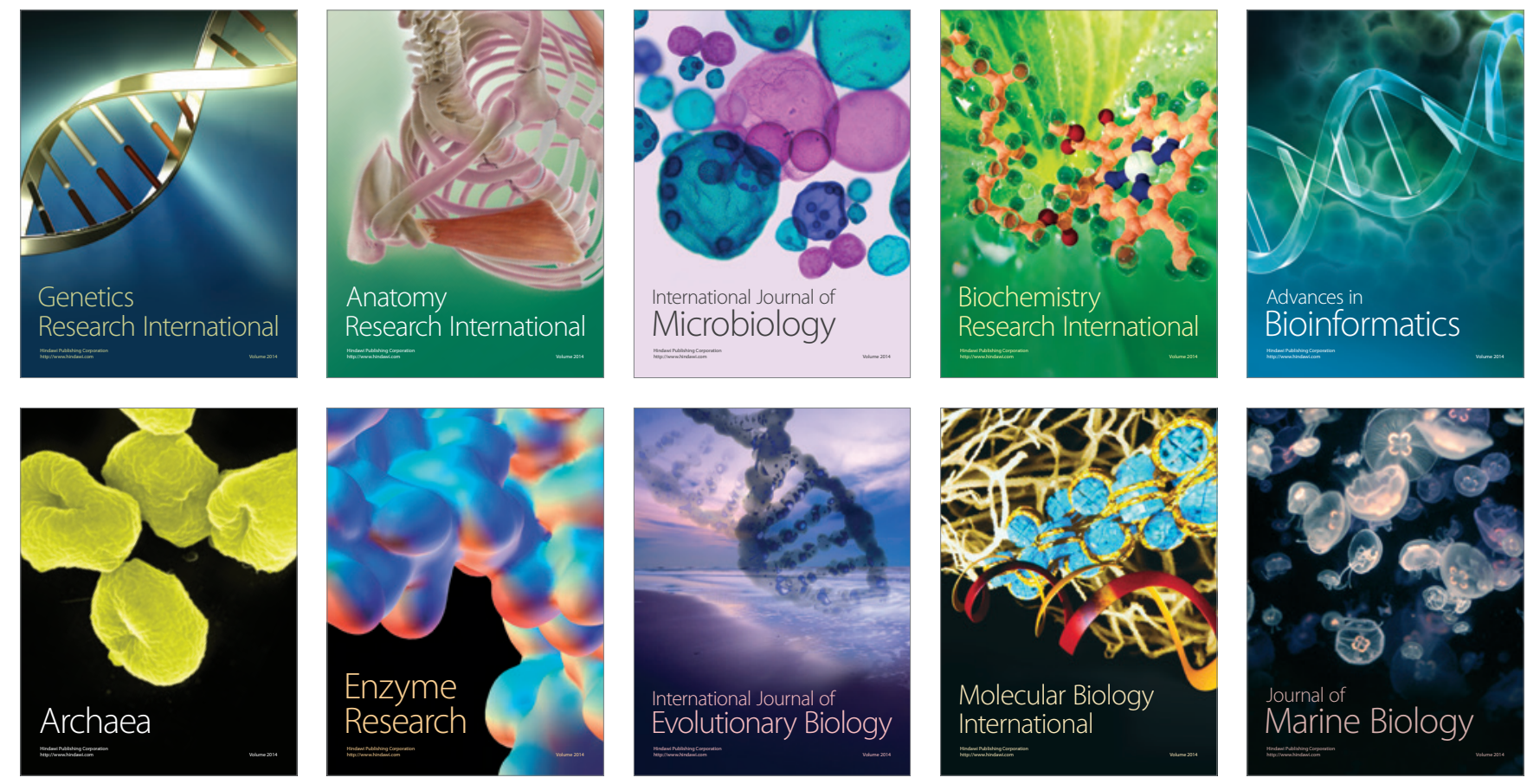